\title{
Clinical Characteristics of Epidermoid Cysts of the External Auditory Canal
}

\author{
Go-Woon Kim, Jang-Hee Park, Oh-Joon Kwon, Dong Hyun Kim, and Chang Woo Kim \\ Department of Otorhinolaryngology-Head \& Neck Surgery, College of Medicine, Hallym University, Seoul, Korea
}

Received October 27, 2015

Revised December 30, 2015

Accepted January 21, 2016

Address for correspondence Chang Woo Kim, MD

Department of Otorhinolaryngology-

Head \& Neck Surgery,

College of Medicine,

Hallym University,

150 Seongan-ro, Gangdong-gu,

Seoul 05355, Korea

Tel +82-2-2224-2279

Fax +82-2-482-2279

E-mail kcw5088@dreamwiz.com
Background and Objectives: The epidermoid cyst is a common benign disease of the skin caused by inflammation of hair cortex follicles and proliferation of epidermal cells within the dermis or superficial subcutaneous tissue. The purpose of this study was to investigate the characteristics of epidermoid cysts of the external auditory canal (EAC) by analyzing the clinical and radiologic features. Subjects and Methods: The clinical records were retrospectively reviewed for patients diagnosed with epidermoid cyst of the EAC from March 2004 to December 2013. The epidermoid cysts were diagnosed clinically by endoscopy and microscopy examinations and by temporal bone CT images, and were confirmed by histopathologic examination. Characteristics of epidermoid cysts in bony EAC and cartilaginous EAC were compared. Results: Eight patients had an epidermoid cyst in the bony EAC and nine patients had one in the cartilaginous EAC. Swelling and otalgia were common symptoms, but $47 \%$ of cysts were found incidentally. The mean age of patients was 49.6 years (age range, 26-67 years) in the bony EAC cases and 26.1 years (age range, 6-57 years) in the cartilaginous EAC cases. The mean size of the epidermoid cyst was $3.50 \mathrm{~mm}$ (size range, 2-7 $\mathrm{mm}$ ) in the bony EAC cases and $9.55 \mathrm{~mm}$ (size range, 2-20 $\mathrm{mm}$ ) in the cartilaginous EAC cases. Conclusions: Comparison of epidermoid cysts of the bony EAC and the cartilaginous EAC revealed that epidermoid cysts of the bony EAC is usually found incidentally, arose in older patients and had smaller size.

J Audiol Otol 2016;20(1):36-40

\section{Introduction}

The epidermoid cyst is a common benign disease of the skin caused by inflammation of hair cortex follicles and proliferation of epidermal cells within the dermis or superficial subcutaneous tissue [1]. It usually arises on hair-bearing areas including the scalp, face, neck, trunk, extremities, and scrotum [2]. The cyst is filled with keratin and lined with stratified squamous epithelium. It is usually a slow-growing mass that ranges in size from a few millimeters to several centimeters. The epidermoid cyst may remain small for years or may grow rapidly. It is usually asymptomatic, but sometimes it may cause cosmetic problems or inflammation when the cyst wall ruptures into the subcutaneous tissue [3]. Ab-

This is an Open Access article distributed under the terms of the Creative Commons Attribution Non-Commercial License (http://creativecommons. org/licenses/by-nc/3.0/) which permits unrestricted non-commercia use, distribution, and reproduction in any medium, provided the original work is properly cited. scess formation, hemorrhage, and malignant transformation have been reported as complications of epidermoid cysts [4]. Despite the rarity of coincident malignancy in an epidermoid cyst, cystic skin lesions that are large, rapidly changing in size, inflamed, or painful should be examined histopathologically to exclude malignancy [5].

Epidermoid cysts of the external auditory canal (EAC) are rare, but when they occur, they may cause hearing disturbances by obstruction of the EAC or promote otalgia, a recurrent infection. Abdel-Aziz [6] reported nine cases of epidermoid cyst of the cartilaginous EAC in pediatric patients. All were observed as swelling in the EAC by the patients' parents. Epidermoid cysts of the bony EAC are extremely rare because the medial bony EAC is devoid of sebaceous glands and hair follicles, and only four cases have been reported in the English-language literature [4,7-9]. Most of these cases had extensive bony erosion, but the authors stated that they differed from cholesteatoma of the EAC and were a form of 
epidermoid cyst. However, extensive destruction of bone by an epidermoid cyst is doubtful. Cholesteatoma destroys the bone through osteoclastic bone resorption and chronic inflammation, whereas the epidermoid cyst seems to erode adjacent bone through pressure necrosis [10]. Clark, et al. [11] suggested that epidermoid cyst and cholesteatoma are the same disease entity because they are indistinguishable histopathologically as well as radiologically. Lee [4] described different findings in an imaging study that compared cholesteatoma and epidermoid cysts. But their suggestions were based on a case report, so further analysis of a large case series is still needed.

In this study, we investigated the characteristics of the epidermoid cyst of the EAC by analyzing the clinical and radiologic features. We also compared the differences between epidermoid cysts arising in bony EAC and in cartilaginous EAC.

\section{Subjects and Methods}

The clinical records were retrospectively reviewed for patients diagnosed with epidermoid cyst of the EAC at a tertiary referral center between March 2004 and December 2013. The epidermoid cysts were diagnosed clinically by endoscopy and microscopy examinations and by temporal bone computed tomography (CT) images, and were confirmed by histopathologic examination. We analyzed the main symptoms and clinical findings of the epidermoid cysts, such as location, localization, size, and treatment outcomes for evalua- tion of characteristics of the epidermoid cysts of the EAC. Location was defined as the wall involved with epidermoid cyst, according to the endoscopy and microscopy findings, with the umbo as a pivot and the manubrium of the malleus as a baseline of the angle: anterior between 45 and 135 degrees, inferior between 135 and 225 degrees, posterior between 225 and 315 degrees, and superior between 315 and 45 degrees. Localization was classified as bony and cartilaginous according to the distribution of the epidermoid cyst. We compared the characteristics of epidermoid cyst in bony EAC and cartilaginous EAC. Size was determined based on measurements taken from a photograph of each specimen after excision, taking the measurement of the major axis and of the minor axis at right angles to the major axis and calculating the mean value of the two measurements [3]. When the epidermoid cyst was ruptured during the excision, the size of the cyst was determined based on the measurements obtained from the temporal bone CT scan. A pure tone audiogram was taken and the mean values for frequencies $0.5,1,2$, and 3 $\mathrm{kHz}$ were calculated for a hearing test. Statistical analysis was performed using SPSS version 18.0 (SPSS Inc., Chicago, IL, USA). Variables were summarized as means \pm standard deviation. The Mann-Whitney U test was used if the data were continuous variable. Fisher's exact test was used to analyze categorical variables. Two-sided $p$-values of less than 0.05 were considered statistically significant.

This study protocol conformed to the ethical guidelines of

Table 1. Characteristics of epidermoid cysts of the external auditory canal

\begin{tabular}{|c|c|c|c|c|c|c|c|c|c|c|}
\hline Patient no. & Age (years) & Sex & Side & Symptom & $\begin{array}{c}\text { Hearing level } \\
\mathrm{A} / \mathrm{B}(\mathrm{dB} \mathrm{HL})\end{array}$ & Location & Localization & $\begin{array}{l}\text { Size } \\
(\mathrm{mm})\end{array}$ & Treatment & $\begin{array}{l}\mathrm{F} / \mathrm{U} \\
(\mathrm{mo})\end{array}$ \\
\hline 1 & 32 & $\mathrm{~F}$ & $L$ & Otalgia* & $15 / 10$ & $P$ & $C$ & 5 & Excision & 8 \\
\hline 2 & 39 & $\mathrm{~F}$ & L & Hearing impairment & $35 / 12.5$ & $\mathrm{PI}$ & C & 20 & Excision $^{\dagger}$ & 26 \\
\hline 3 & 26 & $\mathrm{~F}$ & L & Palpable mass & $12.5 / 10$ & । & B & 4 & Excision & 8 \\
\hline 4 & 6 & $M$ & L & Otalgia* & $10 / 10$ & PS & C & 10 & Excision $^{\dagger+}$ & 12 \\
\hline 5 & 64 & $\mathrm{~F}$ & L & Incidental & $15 / 12.5$ & I & B & 7 & Excision & 4 \\
\hline 6 & 18 & $\mathrm{~F}$ & $R$ & Swelling* & $12.5 / 10$ & । & C & 10 & Excision & 6 \\
\hline 7 & 40 & $\mathrm{~F}$ & L & Itching sense & $15 / 12.5$ & S & B & 5 & Excision & 8 \\
\hline 8 & 11 & $\mathrm{~F}$ & L & Swelling* & $10 / 7.5$ & । & C & 5 & Excision $^{\dagger}$ & 6 \\
\hline 9 & 8 & $M$ & L & Swelling* & $35 / 15$ & S & C & 10 & Excision $^{\dagger}$ & 8 \\
\hline 10 & 37 & $M$ & L & Swelling & $35 / 12.5$ & S & C & 20 & Excision $^{\dagger}$ & 6 \\
\hline 11 & 67 & $\mathrm{~F}$ & $R$ & Incidental & $37.5 / 32.5$ & $P$ & B & 2 & Excision & 9 \\
\hline 12 & 60 & $M$ & $R$ & Incidental & $45 / 42.5$ & S & B & 2 & Excision & 7 \\
\hline 13 & 27 & $\mathrm{~F}$ & $R$ & Incidental & $15 / 12.5$ & 1 & C & 4 & Excision & 6 \\
\hline 14 & 57 & $\mathrm{~F}$ & $R$ & Incidental & $20 / 15$ & A & C & 2 & Excision & 8 \\
\hline 15 & 40 & $M$ & $R$ & Incidental & $15 / 15$ & $S$ & B & 2 & Excision & 6 \\
\hline 16 & 45 & $\mathrm{~F}$ & $R$ & Incidental & $15 / 12$ & S & B & 4 & Excision & 8 \\
\hline 17 & 55 & $M$ & $\mathrm{~L}$ & Incidental & $20 / 15$ & I & B & 2 & Excision & 6 \\
\hline
\end{tabular}

* combined with infection, ${ }^{\dagger}$ operated under general anesthesia, ${ }^{\dagger}$ cyst wall ruptured during operation. M: male, F: female, R: right, L: left, A/B: air conduction/bone conduction, P: posterior, I: inferior, S: superior, A: anterior, B: bony, C: cartilaginous, F/U: followed up, mo: month 
the 1975 Declaration of Helsinki.

\section{Results}

Seventeen patients (6 males and 11 females) with epidermoid cysts of the EAC were included in the study (Table 1). All patients had an intact tympanic membrane, and none had prior trauma, otologic surgery, or ear canal anomaly. The mean age of patients was 37.1 years (age range, 6-67 years) and every patient had a single, unilateral epidermoid cyst. Swelling and otalgia were common symptoms, but cysts in $47 \%$ of patients were found incidentally. Five patients had a combined infection around the cyst. Three patients had a conductive hearing loss due to obstruction of the EAC by the epidermoid cyst. The superior and inferior walls were commonly involved locations. The mean size of the epidermoid cyst was $6.7 \mathrm{~mm}$ (size range, $2-20 \mathrm{~mm}$ ). Eight patients had an epidermoid cyst in the bony EAC and nine patients had one in the cartilaginous EAC. The epidermoid cyst was covered with intact healthy skin and localized within the EAC (Fig. 1A). CT showed a cystic mass in the lumen of the EAC without bony erosion (Fig. 1B). Three cases of epidermoid cyst were ruptured during excision; however, the lining wall was removed completely. The epidermoid cysts were round and their walls were white (Fig. 1C). Histopathologic examination of every patient showed that the cyst was lined with squamous epithelium containing laminated keratin material, which was compatible with an epidermoid cyst (Fig. 1D). The mean follow-up period was 8.3 months (follow-up range, 4-26 months). No complications were reported during or after removal of the cysts, and no recurrences developed during the follow-up period.

\section{Comparison between the epidermoid cysts in bony EAC and in cartilaginous EAC (Table 2)}

The mean age of patients was 49.6 years (age range, 26-67 years) in the bony EAC cases and 26.1 years (age range, 6-57 years) in the cartilaginous EAC cases. The mean size of the epidermoid cyst was $3.50 \mathrm{~mm}$ (size range, 2-7 $\mathrm{mm}$ ) in the bony EAC cases and $9.55 \mathrm{~mm}$ (size range, 2-20 $\mathrm{mm}$ ) in the cartilaginous EAC cases. The mean age and mean size of the epidermoid cyst showed statistically significant differences between the epidermoid cysts arising in bony EAC and in the cartilaginous EAC. The epidermoid cysts in six patients $(75 \%)$ with cysts in the bony EAC were found incidentally during evaluation of other ear discomfort; for example, otalgia or tinnitus of the ear on the other side (Fig. 1). Four patients $(44 \%)$ with the epidermoid cyst in the cartilaginous EAC had a swollen EAC (Fig. 2) and two patients (22\%) had an otalgia. Among the cartilaginous cases, five patients had a combined external ear infection around the cyst and three patients had a conductive hearing loss due to obstruction of the EAC.

\section{Discussion}

Epidermoid cysts can be congenital or acquired; congenital epidermoid cysts may be due to entrapment of ectodermal
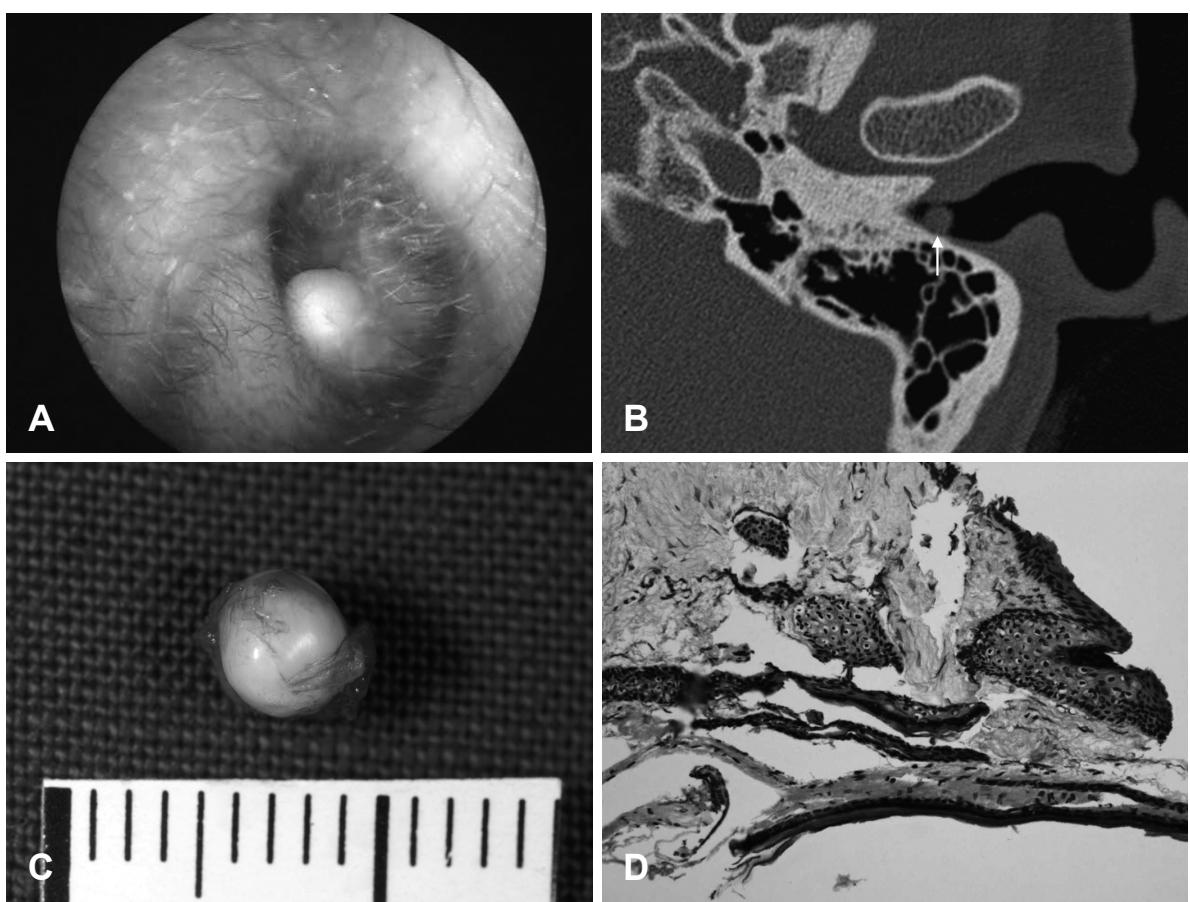

Fig. 1. Pictures of case no. 4. A: Otoscopic image reveals a silver-colored spherical mass on the bony portion of the left external auditory canal (EAC). B: Temporal bone computed tomography image shows a round mass (arrow) on the bony portion of the EAC. Note that no bony erosion is evident. C: The mass was spherical shaped and easily separated from the EAC skin. D: Histopathologic image reveals that the mass is lined with squamous epithelium and contains keratin material (hematoxylin-eosin stain, $\times 100$ ). 
elements intradermally or subcutaneously during fusion of the first and second branchial arches [6]. Acquired cysts derive from traumatic or iatrogenic implementation of epidermal cell proliferation into the dermis due to penetrating injury, or occlusion of a sebaceous gland duct in the hair follicle

Table 2. Comparison of ECs in bony EAC and cartilaginous EAC

\begin{tabular}{|c|c|c|c|}
\hline & $\begin{array}{l}E C \text { in bony } \\
E A C(n=8)\end{array}$ & $\begin{array}{c}E C \text { in cartilaginous } \\
\text { EAC }(n=9)\end{array}$ & $\begin{array}{c}p \\
\text { value }\end{array}$ \\
\hline Sex & & & $1.000^{\dagger}$ \\
\hline Male & 3 & 3 & \\
\hline Female & 5 & 6 & \\
\hline Age (years) & $49.6 \pm 14.19$ & $26.1 \pm 16.96$ & $0.009^{中}$ \\
\hline Side & & & $0.637^{\dagger}$ \\
\hline Left & 4 & 6 & \\
\hline Right & 4 & 3 & \\
\hline Symptom & & & $0.015^{\dagger}$ \\
\hline Otalgia & & 2 & \\
\hline Swelling & & 4 & \\
\hline Palpable mass & 1 & & \\
\hline Itching sense & 1 & & \\
\hline Hearing impairment & & 1 & \\
\hline Incidental & 6 & 2 & \\
\hline Location* & & & $0.903^{\dagger}$ \\
\hline Superior & 4 & 3 & \\
\hline Anterior & & 1 & \\
\hline Inferior & 3 & 4 & \\
\hline Posterior & 1 & 3 & \\
\hline \multicolumn{4}{|l|}{ Hearing level } \\
\hline Normal & 6 & 6 & 0.100 \\
\hline Conductive $\mathrm{HL}$ & & 3 & \\
\hline Sensorineural HL & 2 & & \\
\hline Size $(\mathrm{mm})^{\phi}$ & $3.5 \pm 1.85$ & $9.55 \pm 6.59$ & 0.018 \\
\hline Follow-up (month) ${ }^{\dagger}$ & $7.0 \pm 1.60$ & $9.5 \pm 6.46$ & 0.651 \\
\hline
\end{tabular}

The values of age, size and follow-up are values are means \pm SD. A $p$-value $<0.05$ value was set as the significance level. *two patients with multiple locations in cartilaginous group, ${ }^{\dagger}$ the Fisher's exact test was used to analyze the sex, side, symptom, and location, "the Mann-Whitney $U$ test was used to analyze the age, size, and follow-up. EAC: external auditory canal, EC: epidermoid cyst, HL: hearing loss, SD: standard deviation
[1]. Tympanomastoid surgery may cause a traumatic epidermoid cyst as a complication [12,13]. Although these cysts are frequently found on the scalp, face, neck, trunk, extremities, and scrotum, they may occur anywhere on hair-bearing skin [2]. However, their appearance in the EAC is very rare. Abdel-Aziz [6] reported nine cases of epidermoid cyst of the cartilaginous EAC in pediatric patients. Although the patients' ages differed between Abdel-Aziz' [6] report and our report, the sizes and symptoms of the cysts were similar.

The skin of the EAC shows marked differences in morphology between the bony canal and cartilaginous canal. The skin of the bony canal is very thin; measuring about $0.2 \mathrm{~mm}$ in thickness. The skin of the bony canal lacks hairs and other skin appendages. By contrast, the skin of the cartilaginous canal is much thicker $(0.5-1.0 \mathrm{~mm})$ and the epidermis is composed of four layers [14]. It has numerous hairs as well as sebaceous and ceruminous glands. Therefore, epidermoid cysts of the bony EAC are extremely rare because the medial bony EAC is devoid of sebaceous glands and hair follicles. Four cases of epidermoid cysts of the bony EAC have been reported as a case presentation [4,7-9]. The ages of the patients ranged from 3 to 25 years. The sizes of the cysts ranged from 7 to $20 \mathrm{~mm}$ and were associated with wide erosion of the bony EAC. In our study, eight cases arose in the bony EAC, but none had bony erosion. The ages of our patients ranged from 26 to 67 years and the size of the cysts ranged from 2 to $7 \mathrm{~mm}$. Two patients had a sensorineural hearing loss, which may have been due to the aging process. Epidermoid cysts in our study arose in older patients and showed smaller size. We feel that repeated minor trauma to the bony canal may play an important role in the development of epidermoid cyst; the skin of the bony EAC is loosely attached to the underlying bone, so it is quite vulnerable to trauma. Epidermoid cysts of the bony EAC had several characteristics that contrasted with cysts of the cartilaginous EAC. The mean age of the patients was older and the size of the cyst was smaller. Epidermoid cysts of the bony EAC were usually found incidentally, whereas swelling and otalgia were com-
Fig. 2. Pictures of case no. 10. A: The picture reveals a flesh-colored spherical mass on cartilaginous portion of the left external auditory canal (EAC). B: The image of computed tomography with enhancement shows a round mass (arrow) on the cartilaginous portion of the EAC without enhancement.
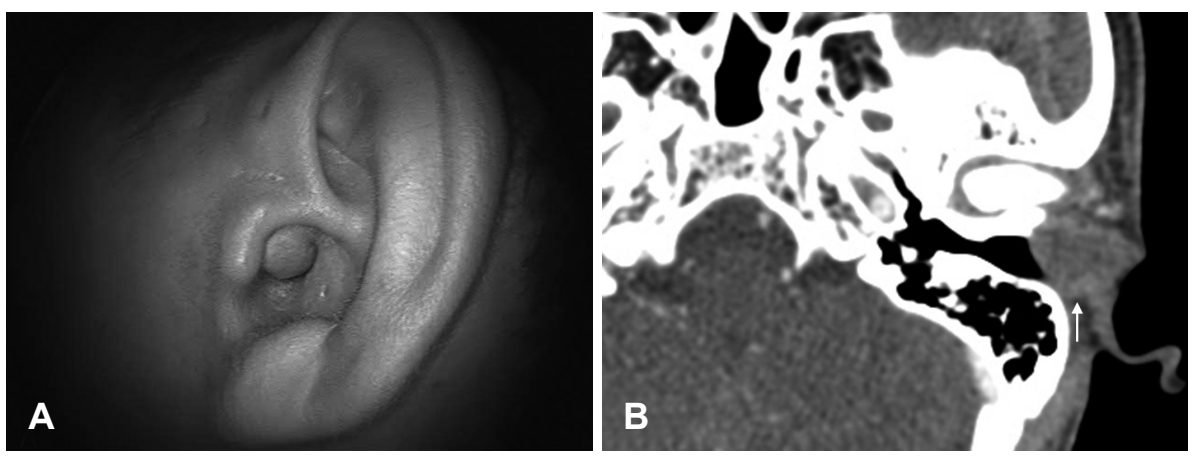
mon symptoms of epidermoid cysts of the cartilaginous EAC. The differential diagnosis of an epidermoid cyst in the EAC includes EAC cholesteatoma, dermoid cyst, inflammatory polyp, and soft tissue tumors such as hemangioma, lipoma, meningioma, and acoustic neuroma [4]. The dermoid cyst is a benign congenital lesion that consists of stratified epithelium lined by laminated keratin material containing adnexal structures of skin, such as sebaceous glands, sweat glands, hair follicles, and hair [1]. An inflammatory polyp may arise from the middle ear and appear as a mass in the EAC. Soft tissue tumors are usually combined with bony erosive changes or enhancement on contrast-enhanced magnetic resonance (MR) images whereas the epidermoid cyst shows thin-rim enhancement in MR images [2]. Among these alternative diagnoses, EAC cholesteatoma is the most difficult disease to differentiate clinically, radiologically, and histopathologically from epidermoid cyst [4]. Although Clark, et al. [11] suggested that epidermoid cyst and cholesteatoma are the same disease entity because they are indistinguishable histopathologically as well as radiologically, these are different diseases. EAC cholesteatoma is characterized by keratin debris, hyperproliferative epithelium, intact basement membrane, and accumulation of inflammatory cells [15]. However, cholesteatoma destroys the bone through osteoclastic bone resorption and chronic inflammation, whereas the epidermoid cyst seems to erode adjacent bone through pressure necrosis [10]. Consequently, CT findings of the epidermoid cyst show a rounder, well-demarcated contour, and the boundaries between adjacent bones is clearer and smooth [4]. Cholesteatoma mostly shows as a sharply marginated, expansile mass, but the mass margin is usually irregular and scalloped and accompanied by varying degrees of bony erosion [4].

In conclusion, the mean age of the patient is older and the size of the cyst is smaller in epidermoid cysts of the bony EAC. These are also usually found incidentally, whereas swelling and otalgia were common symptoms of the epidermoid cyst of the cartilaginous EAC. These differences may be due to discrepancy in morphology that the skin of the bony canal is much thinner and more loosely attached to the underlying tissue than the skin of the cartilaginous canal.

\section{Conflicts of interest}

The authors have no financial conflicts of interest.

\section{REFERENCES}

1) Jung KH, Choi HJ, Nam DH. Characteristics of dermoid cyst of the auricle. Arch Craniofac Surg 2014;15:22-7.

2) Kim HK, Kim SM, Lee SH, Racadio JM, Shin MJ. Subcutaneous epidermal inclusion cysts: ultrasound (US) and MR imaging findings. Skeletal Radiol 2011;40:1415-9.

3) Park JS, Ko DK. A histopathologic study of epidermoid cysts in Korea: comparison between ruptured and unruptured epidermal cyst. Int J Clin Exp Pathol 2013;6:242-8.

4) Lee DH. Intradiploic epidermoid cyst of the temporal bone: is it the same as or different from cholesteatoma? J Craniofac Surg 2011;22: 1973-5.

5) Shabbir A, Loss L, Bogner P, Zeitouni NC. Squamous cell carcinoma developing from an epidermoid cyst of the ear. Dermatol Surg 2011;37:700-3.

6) Abdel-Aziz M. Epidermoid cyst of the external auditory canal in children: diagnosis and management. J Craniofac Surg 2011;22:1398-400.

7) Alimoglu Y, Mercan H, Karaman E, Oz B. Epidermal inclusion cyst of external auditory canal. J Craniofac Surg 2010;21:1290-1.

8) Suzuki T, Taki M, Shibata T, Matsunami T, Sakaguchi H, Yamamoto $\mathrm{S}$, et al. Epidermal cyst of the bony external auditory canal. Otolaryngol Head Neck Surg 2007;136:155-6.

9) Yu WN, Fu SC, Lai JC. Epidermal cyst of the bony external auditory canal. Kaohsiung J Med Sci 2013;29:237-8.

10) Warren FM, Bennett ML, Wiggins RH 3rd, Saltzman KL, Blevins $\mathrm{KS}$, Shelton C, et al. Congenital cholesteatoma of the mastoid temporal bone. Laryngoscope 2007;117:1389-94.

11) Clark MP, Pretorius PM, Beaumont D, Milford CA. Congenital cholesteatoma of occipital bone or intradiploic epidermoid cyst? One and the same disease. J Laryngol Otol 2009;123:673-5.

12) Tovi F, Bartal N, Zirkin C. Epidermal cysts of temporal fossa: an unusual complication of ear surgery. Ann Otol Rhinol Laryngol 1985; 94(2 Pt 1):162-4.

13) Ulku CH, Uyar Y, Kocaogullar Y, Avunduk MC. Iatrogenic epidermal inclusion cyst of the parapharyngeal space: unusual complication of ear surgery. Skull Base 2004;14:47-51; discussion 51.

14) Alvord LS, Farmer BL. Anatomy and orientation of the human external ear. J Am Acad Audiol 1997;8:383-90.

15) Naim R, Linthicum F Jr, Shen T, Bran G, Hormann K. Classification of the external auditory canal cholesteatoma. Laryngoscope 2005; $115: 455-60$ 